\title{
Sudden infant death syndrome: seasonality and a biphasic model of pathogenesis
}

\author{
Anne-Louise Ponsonby, Terence Dwyer, Michael Edwin Jones
}

\begin{abstract}
Study objective-This paper examines the relationship between season, age, and the sudden infant death syndrome (SIDS). It provides a theoretical model for the pathogenesis of SIDS and uses it as a framework to consider risk factor mechanism.
\end{abstract}

Design-A case series analysis was used to examine season and age in relation to SIDS and seasonal pattern and age at death distribution of perinatal risk factors.

Setting-The source population for the siDs cases in this study was all live births in the state of Tasmania, Australia, 1975 to 1987 inclusive.

Subjects-Cases were all infants born 1975 to 1987 who died of SIDS on whom birth notification information was available $(n=348)$. The live birth cohort $1980-87$ $(n=55944)$ was used as the control population for risk factor identification.

Measurements and main results-The median ages of death for spring, summer, autumn, and winter born infants were 115 , 103.5, 91 and 78 days. Spring and summer born infants died at a significantly older median age than winter born infants. The month of birth distribution of SIDS cases did not alter significantly from a uniform, nonseasonal distribution $(p>0.25)$ but month of death was seasonally distributed $(p<0.01)$. Premature and low birthweight infants died at an older median age $(p<0.05)$ than term and non-low-birthweight infants. An excess of male infant deaths and infant deaths to older mothers occurred during winter $(\mathbf{p}<0.05)$.

Conclusions-The pathogenesis of SIDS can be represented as a biphasic model with three pathways of risk factor operation. In this study, season influenced the age at death of SIDS infants. We propose that risk factors with a strong seasonal distribution are likely to be operating in the postnatal period.

Menzies Centre for Population Health Research, University of Tasmania, Clinical School, 43 Collins Street, Hobart 7000, Tasmania, Australia A-L Ponsonby T Dwyer M E Jones

Correspondence to: Dr Ponsonby

Accepted for publication April 1991

Although the pathogenesis of the sudden death syndrome (SIDS) remains unclear many researchers believe it to be a biphasic event. Antenatal factors may cause the infant to be physiologically vulnerable. ${ }^{1}$ Such a vulnerable infant may then require environmental loading factors to trigger a sIDs event during the postnatal period. ${ }^{2}$ The age at death distribution of sIDs is unusual, with low risk during the neonatal period, a marked increase from the second until the fourth postnatal month, and a decline thereafter. The age at death distribution is thought to reflect a development physiological process which places the infant at risk of SIDS, although this has been disputed. $^{34}$

Seasonal variation in the incidence of sIDs has been well documented, with an increase in cases during the winter months. Recent work in Sweden and England has concluded that the seasonal pattern of SIDS death is predominantly associated with variation in month of death rather than in month of birth. ${ }^{56}$ Different hypotheses to explain the winter SIDS excess have been proposed. These include an association with viral illness, hypothermia, and hyperthermia. ${ }^{7} \mathrm{~A}$ winter excess of sIDS cases in Tasmania has previously been described. ${ }^{89}$

This paper outlines a study of relationships between season, age, and perinatal risk factors for sIDs. A theoretical model of sIDS pathogenesis is proposed.

\section{Methods}

MATERIALS

This study examined all resident sIDS deaths among infants born in Tasmania during the years 1975 to 1987 inclusive. It was conducted retrospectively by a review of infant records, in particular the database of the Tasmanian obstetric and perinatal audit. ${ }^{10}$

A sIDS case was defined as the sudden death of an infant or young child which is unexpected by history and in which a thorough necropsy examination fails to demonstrate an adequate cause of death. ${ }^{11}$ Among infants born in 19751987 inclusive we identified 353 resident sIDs deaths. All infants dying suddenly and unexpectedly had received a necropsy examination. The sIDs incidence was 3.64 per 1000 live births.

A statutory notification of birth form has been collected on all deliveries since 1974 . It contains sociodemographic, obstetric, and perinatal information. The birth notification database is managed by the Department of Obstetrics and Gynaecology, University of Tasmania and the Tasmanian Department of Health Services. For the time period 1975 to 1987 , birth notification data were obtained on over $99 \%$ of the 96880 live births in the State. Birth notification data were also available on 348 of the 353 infants who later died of sIDS, representing $98.6 \%$ of such infants.
ANALYSIS OF THE DISTRIBUTION OF SIDS CASES BY MONTH OF DEATH

Infant date of birth, date of death, and sex were obtained for the sIDS cases. Frequency tables of adjusted month of birth and adjusted month of 
death were made. Calendar months were not used because of their varying lengths. The months were adjusted to as near even length as possible. sIDs cases occurring in the first 30 days of any year were allocated to month 1 . Cases occurring in the next 30 days were allocated to month 2 , and so on. The exceptions were months $3,5,7,9$, and 11 which covered a 31 day period. During leap years month 12 also had 31 days. Sinusoidal seasonality was tested for by fitting a generalised linear model to the total number of sIDS cases in an adjusted month. The computer program GLIM was used, with a log link function and the error structure specified as Poisson. ${ }^{12}$

THE EFFECT OF SEASON OF BIRTH AND SEASON OF DEATH ON THE AGE AT DEATH DISTRIBUTION OF SIDS The adjusted months of birth were grouped into seasons. For example, the adjusted months 1, 2, and 12, corresponding to January, February, and December, were grouped as summer. The age at death distribution was examined for each season of birth. As the age at death distribution is not normally distributed, the median rather than mean age at death was used to describe the average age at death. The rank transformation was used and a conventional analysis of variance conducted $^{13}$ to assess the overall significance of any variation in average ranked age at death for the four seasons of births. The differences between the four groups of infants born in the different seasons with regard to median age at death were examined using the Bonferroni multiple comparison test. ${ }^{14}$ Age at death was also grouped by season of death and analysed in the same way.

Figure 1 SIDS cases by month of birth, Tasmania month of birth

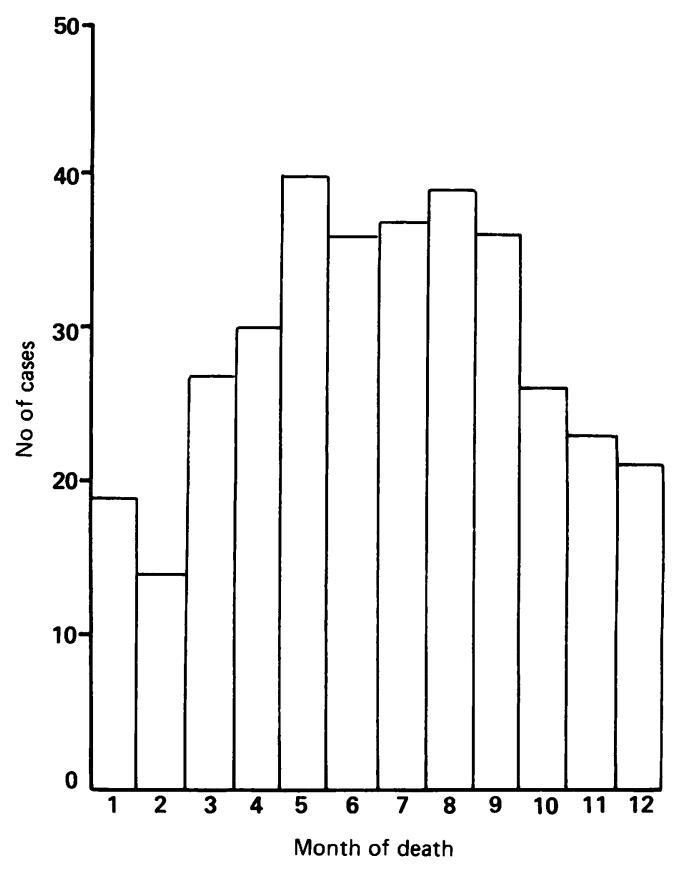

Figure 2 SIDS cases by month of death, Tasmania 1975-1987

THE RELATIONSHIP OF PERINATAL RISK FACTORS FOR SIDS TO SEASON OF DEATH AND AGE AT DEATH

Birth notification details were obtained for the cases $(n=348)$ and a large set of control infants $(n=55944)$. The control group were all infants born live 1980-1987 inclusive. Control infants for earlier years were not selected because their birth notification data were not on the computerised database.

The exposure disease associations of birth notification variables were examined by $2 \times 2$ contingency tables. Unadjusted odds ratios with 95\% Cornfield confidence intervals were calculated for each risk factor. This screening process identified variables which discriminated significantly between cases and controls (table I). For each of the two levels of the identified exposure, seasonal homogeneity of sids cases was examined using the $\chi^{2}$ test. Median age at death was also examined using the Kruskal-Wallis test. $^{15}$

\section{Results}

THE SEASONAL DISTRIBUTION OF SIDS ANALYSED BY MONTH OF BIRTH AND MONTH OF DEATH

Figure 1 shows that the month of birth distribution for sIDS cases did not differ significantly from a uniform, non-seasonal distribution $\left(\chi_{11}^{2}=12 \cdot 7, p>0 \cdot 1\right)$. Further analysis fitted a generalised linear model, specifically looking for sinusoidal seasonality, and detected no significant effect $\left(\chi_{2}^{2}=5 \cdot 2, p>0 \cdot 05\right)$. However, the month of death distribution (figure 2 ) of sIDs cases did display seasonality with a winter peak $\left(\chi_{11}^{2}=27 \cdot 7, p<0.01\right)$. The test for seasonality following a sinusoidal pattern was also significant $\left(\chi_{2}^{2}=24 \cdot 8, \mathrm{p}<0.001\right)$.

THE AGE AT DEATH DISTRIBUTION OF SIDS ANALYSED BY SEASON OF BIRTH AND DEATH

The age at death distribution differed by season of birth (fig 3). Thirty per cent of sids infants born in 


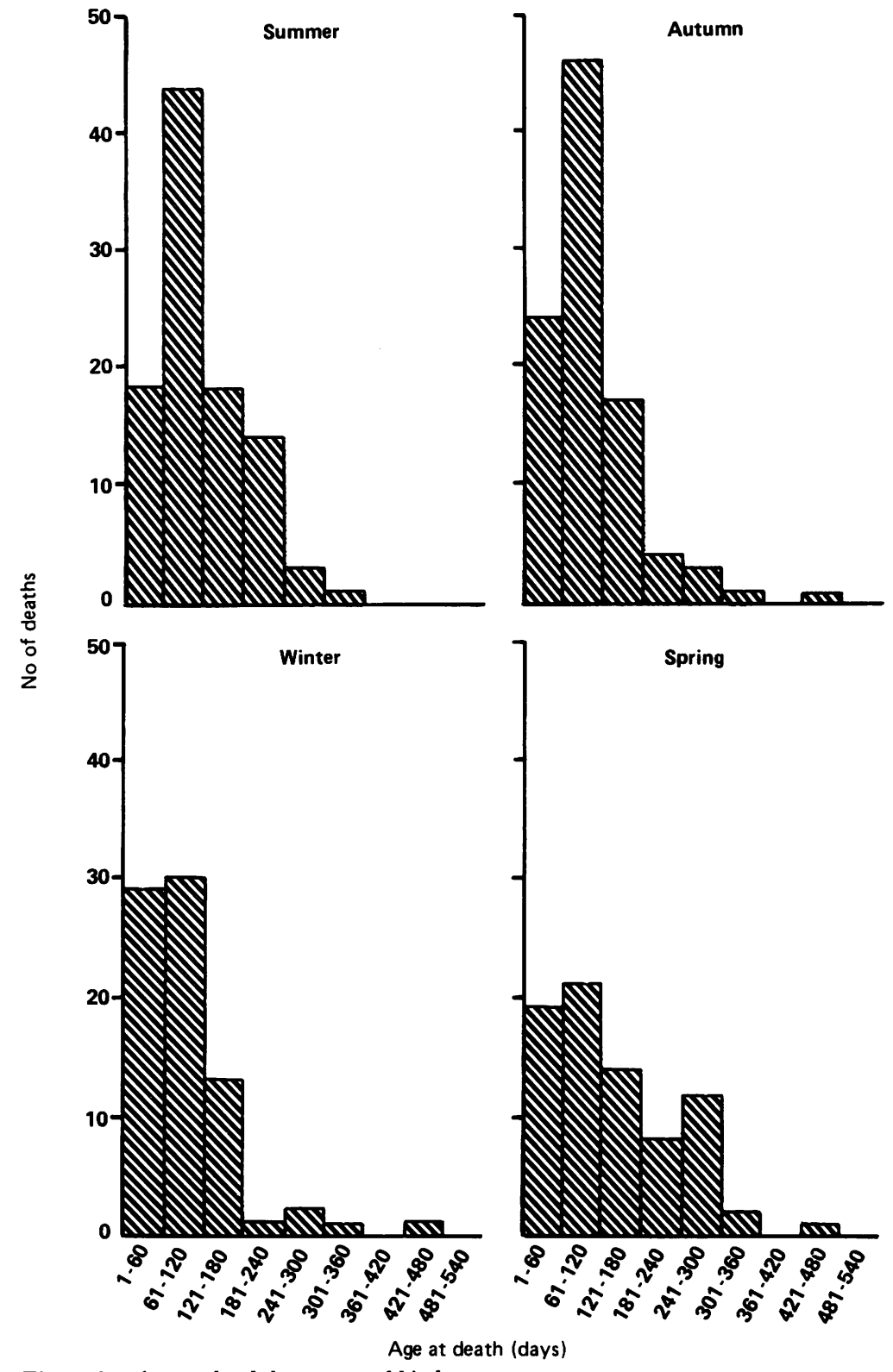

Figure 3 Age at death by season of birth

Table II Median age of death by season of birth and death

\begin{tabular}{llllll}
\hline & & Season & & \\
\cline { 2 - 5 } & Spring & Summer & Autumn & Winter \\
\hline $\begin{array}{l}\text { Season of } \\
\text { birth: }\end{array}$ & $\begin{array}{l}\text { Median age at } \\
\text { death in days }\end{array}$ & 115 & 103.5 & 91 & 78 \\
\cline { 2 - 5 } $\begin{array}{l}\text { Season of } \\
\text { death: }\end{array}$ & $\begin{array}{l}\text { Median age at } \\
\text { death in days }\end{array}$ & 95 & 73 & 95 & 96.5 \\
\cline { 2 - 5 }
\end{tabular}

Using the Bonferroni multiple comparison test, the seasons joined by a solid line are no significantly different. Overall multiple comparison significance level is five per cent. spring and $17 \%$ of sIDs born in summer died at an age greater than six months. This compares with $9 \%$ and $6 \%$ of sIDs infants born in autumn and winter respectively. The median ages of death for spring, summer, autumn, and winter born infants were $115,103 \cdot 5,91$ and 78 days respectively. The multiple comparison test concluded that spring and summer born infants died at a significantly older age than winter born infants (table II). However, the age at death distribution did not differ by season of death. None of the differences between the median ages of death for each pairwise comparison of seasons of death were significant at the $5 \%$ level. The median age at death did not differ significantly by season of death when the overall variation was considered [ $F$ test: $F$ value $(3,344)=1 ; p>0 \cdot 4]$.

THE RELATIONSHIP OF PERINATAL RISK FACTORS FOR SIDS TO SEASON OF DEATH AND AGE AT DEATH The seasonal patterns of the perinatal characteristics of the sIDS infants are outlined in table III. The seasonal distribution of each risk factor is compared to the seasonal pattern of the corresponding reference group. The risk factor "male sex" showed a stronger seasonal pattern $\left(\chi_{3}^{2}=22.90, \quad \mathrm{p}<0.0001\right)$ and higher winter: summer ratio $\left(\chi_{1}^{2}=4.62, p<0.05\right)$ than the reference group of female infants. Female infants did not show a seasonal pattern $\left(\chi_{3}^{2}=3.60\right.$. $p>0.05)$. sIDs infants born to young mothers $(<20$ years $)$ showed no seasonal pattern $\left(\chi_{3}^{2}=1.71, p>0.05\right)$ and a lower winter:summer ratio $\left(\chi_{1}^{2}=5 \cdot 1, p<0.05\right)$ than the sIDs infants born to older mothers.

The median age at death was calculated for each of the risk factors. Premature infants ( $<36$ weeks) died at an older median age (112 days) than non-premature infants (92 days). Low birthweight infants $(<2500 \mathrm{~g})$ died at an older median age (114.5 days) than heavier infants (91 days). The difference in median age at death was significant at the 5\% level for these two groups. No significant difference was found between the median age at death for the following variables when compared to their reference groups: maternal age $<20$ years, male infant sex, multiple birth, multiparity.

\section{Discussion}

This study found the month of death distribution of the sIDs cases to be seasonally distributed but the month of birth distribution not to differ significantly from a uniform, non-seasonal

Table III SIDS cases 1975-1987: Perinatal characteristics and season of death

\begin{tabular}{|c|c|c|c|c|c|c|c|c|}
\hline \multirow[b]{2}{*}{ Perinatal characteristic } & \multirow[b]{2}{*}{$n$} & \multirow[b]{2}{*}{$W: S$ ratio } & \multicolumn{4}{|c|}{ Season of death } & \multicolumn{2}{|c|}{ Seasonal heterogeneity } \\
\hline & & & Summer $\left({ }^{o}, o\right)$ & Autumn $(\%)$ & Winter $(\%)$ & Spring $(\%)$ & $\chi_{3}^{2}$ & p value \\
\hline $\begin{array}{l}\text { Male } \\
\text { Female } \\
\text { Birthweight }<2500 \mathrm{~g} \\
\text { Birthweight } \geqslant 2500 \mathrm{~g} \\
\text { Gestation } \leqslant 36 \text { weeks } \\
\text { Gestation }>36 \text { weeks } \\
\text { Multiple birth } \\
\text { Single birth } \\
\text { Multiparity } \\
\text { Primiparity } \\
\text { Maternal age }<20 \text { years } \\
\text { Maternal age } \geqslant 20 \text { years }\end{array}$ & $\begin{array}{c}212 \\
136 \\
50 \\
298 \\
33^{\mathrm{a}} \\
315 \\
15^{\mathrm{a}} \\
333 \\
242 \\
106 \\
70 \\
278\end{array}$ & $\begin{array}{l}2 \cdot 9 \\
1 \cdot 3 \\
1 \cdot 6 \\
2 \cdot 1 \\
1 \cdot 4 \\
2 \cdot 1 \\
6 \cdot 0 \\
2 \cdot 0 \\
2 \cdot 5 \\
1 \cdot 4 \\
1 \cdot 1 \\
2 \cdot 5\end{array}$ & $\begin{array}{r}12 \\
21 \\
14 \\
16 \\
15 \\
16 \\
7 \\
16 \\
14 \\
20 \\
23 \\
14\end{array}$ & $\begin{array}{l}27 \\
29 \\
36 \\
26 \\
39 \\
27 \\
20 \\
28 \\
31 \\
22 \\
31 \\
27\end{array}$ & $\begin{array}{l}34 \\
29 \\
22 \\
34 \\
21 \\
33 \\
40 \\
32 \\
34 \\
28 \\
24 \\
34\end{array}$ & $\begin{array}{l}27 \\
21 \\
28 \\
24 \\
24 \\
24 \\
33 \\
24 \\
22 \\
30 \\
21 \\
25\end{array}$ & $\begin{array}{r}22 \cdot 90 \\
3 \cdot 60 \\
5 \cdot 02 \\
20 \cdot 10 \\
4 \cdot 21 \\
20 \cdot 44 \\
3 \cdot 60 \\
18 \cdot 70 \\
24 \cdot 00 \\
4 \cdot 70 \\
1 \cdot 71 \\
24 \cdot 10\end{array}$ & $\begin{array}{l}\mathrm{p}<0.001 \\
\text { NS } \\
\text { NS } \\
\mathrm{p}<0.001 \\
\text { NS } \\
\mathrm{p}<0.001 \\
\text { NS } \\
\mathrm{p}<0.001 \\
\mathrm{p}<0.001 \\
\mathrm{NS} \\
\mathrm{NS} \\
\mathrm{p}<0.001\end{array}$ \\
\hline
\end{tabular}

Some cell sizes are less than 5

Null hypothesis = uniform seaonal distribution (ie, no seasonal variation) $\mathrm{Df}=3$

$\mathrm{W}: \mathrm{S}$ ratio $=$ winter cases:summer cases 
distribution. A seasonality analysis by HelwegLarsen et al found that month of death but not month of birth independently influenced the risk of an infant dying of sIDs. ${ }^{5}$ Osmond and Murphy using a large sIDs data set of 6229 cases found a small but independent month of birth effect in addition to the larger effect of month of death on seasonality. ${ }^{6}$ These findings suggest that the seasonal distribution of SIDS is likely to be mediated mainly through postnatal factors.

Age at death reflects the link between date of death and date of birth. As this study found month of birth to be uniformly distributed and month of death to be seasonally distributed, one would expect the infant age at death to be seasonally distributed. Consistent with this, a significant difference in median age at death by season of birth was found.

Previous studies have revealed a tendency for summer born infants to die at older ages but have not established this tendency to be statistically significant by using a multiple comparison test. ${ }^{16-20}$ This study found that spring and summer born infants died at a significantly older age than winter born infants. Our finding that infant age at death is dependent on infant season of birth would support Carpenter and Gardner's impression that "whether infants at risk die depends on environmental factors". ${ }^{17}$ In Tasmania, these environmental factors appear to be largely related to the winter season. Thus there is a tendency for vulnerable "at risk" infants born in spring to survive until additional loading environmental factors occur (in this study $30 \%$ dying at an age greater than six months) whereas infants born in winter, when the environmental loading factors are already present, will die as soon as the critical physiological development phase begins.

In this study, prospectively collected birth notification details were available for over $99 \%$ of live births during the 12 year period, minimising sampling bias. The total live birth cohort of the latter seven years was used as a control group to examine perinatal sIDs risk factors. The selection bias $^{21}$ resulting from this must be considered. Of the six identified sIDS perinatal risk factors, only maternal age altered over time. It increased from

Extrinsic

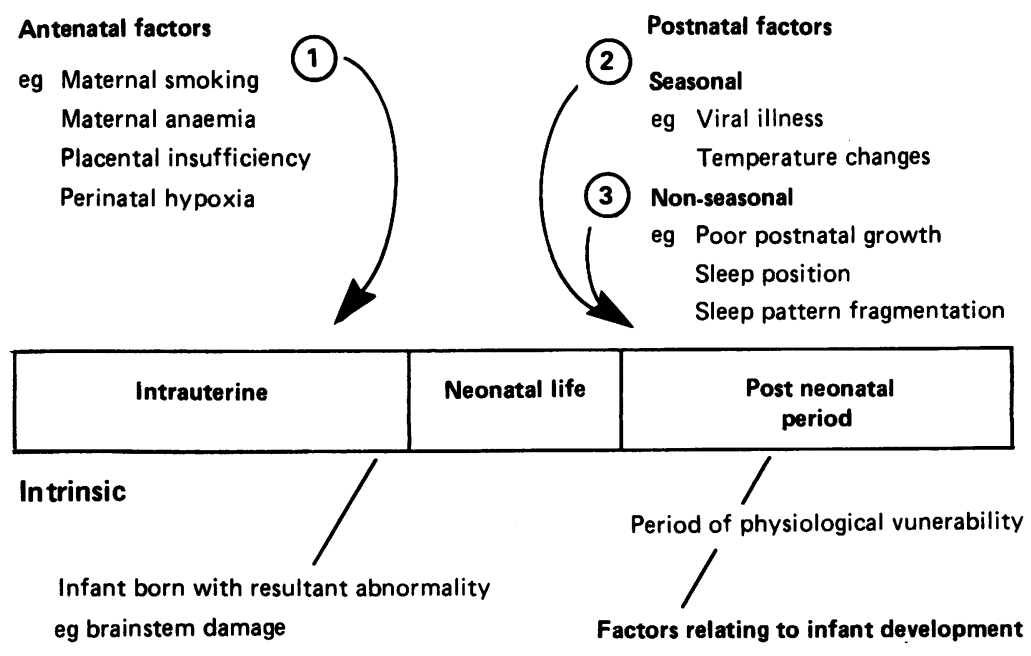

Figure 4 A biphasic model of the pathogenesis of the sudden infant death syndrome. Model based on literature review including reference 7 an average of $25 \cdot 1$ years in 1975 to an average of 27 years in 1987. As the earlier live births (1975-1979) are excluded from controls, not cases, this could have led to an overestimation of the maternal age effect, although the seasonal distribution of this risk factor would not be affected.

The perinatal risk factors identified in this study have all been previously documented. What we currently lack is an understanding of how such risk factors operate on the infant. In this context, a consideration of what the evidence concerning seasonal effect implies about risk factor mechanism becomes important. As the sIDs seasonal pattern is mainly due to variation in infant month of death, it follows that a risk factor with a strong seasonal trend is likely to be operating in the postnatal period.

We propose that the pathogenesis of sids might best be represented as a biphasic model with three pathways for risk factor effects (fig 4). The model takes into account that the syndrome may be multifactorial in aetiology. One could consider an extrinsic risk factor to operate along three possible paths. Firstly, it may operate antenatally. Secondly, it may operate in the postnatal period by increasing the infant's exposure to seasonal environmental triggers. Thirdly, it may operate during the postnatal period but independently of season. Using this model, we can more readily assess how the risk factors "male sex", "young maternal age", "high birth order", and "maternal smoking" may operate.

We found an excess of male deaths to occur during winter. This indicates that the risk factor "male sex" increases risk during the postnatal period of infant life. Male infants are more likely to develop bronchiolitis and pneumonia due to the respiratory syncytial virus. ${ }^{22}$ This virus has been implicated as a precipitating factor in sudden infant death. ${ }^{7}$ However, the factor "young maternal age" is associated with increased risk throughout the year, regardless of season. It is therefore unlikely to be operating in the same way as suggested for "male sex". Evidence from other studies suggests that this factor may operate postnatally, independent of season. Although the relinquishing mothers of adopted infants are young, ${ }^{23}$ the incidence of sIDs in adopted infants has been found to be similar to the incidence in natural born infants. ${ }^{24}$ The risk factor "young maternal age" is therefore unlikely to be acting predominantly in the antenatal period. Social and environmental factors are likely to be important in explaining the difference between the infants of younger and older mothers in postneonatal mortality. Babson and Clarke found the infants of the two maternal age groups to have a similar incidence of lethal malformations and weight specific mortality in the neonatal period, suggesting that biological differences between the two groups are minimal. ${ }^{25}$ Thus one could postulate that the third pathway in the model (ie postnatal, non-seasonal) is involved. For example, young mothers may have different child care practices.

The observation (non-significant) that higher birth order infants are more likely to die in winter than in summer supports the hypothesis that these infants are at higher risk because of increased viral exposure. 
A risk factor for sIDs could act by more than one path. Maternal cigarette smoking has been associated with an increased risk of sIDs. ${ }^{26}$ This risk factor may operate by all three pathways in the model (fig 4). The effect may be mediated antenatally through the association between maternal smoking and intrauterine growth retardation. ${ }^{27}$ Infants of mothers who smoke have higher admission rates for lower respiratory tract infection, particularly during winter. ${ }^{28}$ In addition, maternal smoking could have a direct postnatal toxic effect. Maternal smoking is particularly associated with sIDs infants who are under 12 weeks of age. ${ }^{729} \mathrm{Nicholl}$ and O'Cathain also found that comparatively few young babies had any necropsy evidence of lower respiratory tract disease, suggesting that antenatal smoking rather than postnatal smoking may be more important in these infants. ${ }^{29}$

With regard to infant age, this study found premature infants died of sIDS at a significantly older age than non-premature infants, confirming the work of previous studies, ${ }^{29} 30$ although this relationship has not always been demonstrated. ${ }^{20} 31$ This finding suggests that the sIDS age at death.curve reflects postconceptional rather than postnatal age. Our finding of an older age at death in low birthweight infants probably reflects the close correlation of low birthweight and prematurity.

In conclusion, the pathogenesis of sIDs can be represented by a biphasic model with three pathways of risk factor operation. Seasonality has been considered in relation to risk factor mechanism. In Tasmania, sIDs cases displayed a uniform season of birth distribution and a seasonal month of death distribution. As a consequence the median age at death varied by season of birth. We propose that risk factors with a strong seasonal component are likely to be operating in the postnatal period.

This study was supported by the the Australian Rotary Health Research Fund. Dr A L Ponsonby currently holds a national Health and Medical Research Counci Public Health Scholarship. We thank Professor J Correy, Mrs B Barker, and the Production Committee of the Tasmanian Obstetric and Neonatal Report. Dr N $M$ Newman assisted with regard to case identification and $\mathrm{Mr} \mathrm{N}$ Gilbert provided statistical advice.

1 Naeye RL. Antenatal origin of the sudden death syndrome In: Tildon JT, Roeder L, Steinschneider A, eds. The sudden infant death syndrome. New York: Academic Press, 1983:

2 Bonser RSA, Knight BH, West RR. Sudden infant death syndrome in Cardiff: association with epidemic influenza and temperature-1955-1974. Int $\mathcal{f}$ Epidemiol 1978; 7 $335-40$.

3 Goldberg J, Hornung K, Yamashita T, Wehrmacher $W$ Age at death and risk factors in sudden infant death syndrome. Aust Paediatr $\mathcal{F} 1986 ; 22$ (suppl 1): 21-8.

4 Taylor WB. A single risk factor in sudden infant death and its multiple attack distribution. Int $\mathcal{f}$ Epidemiol 1982; 22: $139-44$.
5 Helweg-Larsen K, Bay H, Mac F. A statistical analysis of the seasonality in sudden infant death syndrome. Int $f$ the seasonality in sudden 19 idem

6 Osmond C, Murphy M. Seasonality in the sudden infant Osmond C, Murphy M. Seasonality in the sudden infant death sync.

7 Golding J, Limerick S, Macfarlane A. In: Sudden infant death. Patterns, puzzles and perspectives. Shepton Mallet: Open Books Publishing Ltd, 198

8 McGlashan N, Grice A. Sudden infant deaths and seasonality in Tasmania, 1970-6. Soc Sci Med 1983; 17 885-8.

9 Newman NM. SIDS in Australia and Tasmania. In Harper RM, Hoffman HJ, eds. Sudden infant death syndrome: risk factors and basic mechanisms. New York: PMA Publishing Corp, 1988: 53-68.

10 Department of Obstetrics and Gynaecology, University of Tasmania. Obstetric and Neonatal Report. Tasmania, 1975-1987.

11 Beckwith B. Discussion of terminology of sudden infant death syndrome. In: Bergman AB, Beckwith JB, Ray CG death syndrome. In: Bergman AB, Beckwith JB, Ray CG, eds. Proceedings of 2nd International conference on causes
of sudden death in infants. Seattle: Universtiy of of sudden death in infants.

12 Payne CD, ed. The GLIM system release 3.77, revision A Oxford: Numerical Algorithms Group, 1986.

13 Conover WJ, Iman RL. Rank transrormation as a bridge between parametric and non parametric statistics. Am Statistician 1981; 35: 124-33.

14 Ingelfinger JA, Mosteller F Thibodeau LA Ware JH Biostatistics in clinical medicine. New York: Macmillan, 1987: 161 .

15 The Kurskal-Wallis test. In: Douglas Montgomery, ed. Design and analysis of experiments. New York: John Wiley \& Sons, 1976: 116-7.

16 Frederick J. Sudden unexpected death in infants in the Oxford record linkage area: Details of pregnancy, delivery axd abnormality in the infant. Br ₹ Prev Soc Med 1974; 28: and abno $164-71$.

17 Carpenter R, Gardner A. Variations in unexpected infan death rates relating to age, sex and season. In: Studies on medical and population subjects. No. 45 Studies in sudden infant deaths. OPCS and London School of Hygiene and Tropical Medicine. London: Her Majesty's Stationery Office, 1982.

18 Kraus J, Borhani N. Postneonatal sudden unexplained death in California: a cohort study. Am $\mathcal{F}$ Epidemiol 1972; 95: 497-510.

19 Hoppenbrouwers T, Calub M, Kazuko A, et al. Seasonal relationship of sudden infant death syndrome and environmental pollutants. $A m$ f Epidemiol 1981; 113: 623-35.

20 Wagner M, Samson-Dollfus D, Menard J. Sudden unexpected infant death in a French county. Arch Dis Child unexpected infant

21 Fletcher RH, Fletcher SW, Wagner EH. Clinical epidemiology-the essentials. Baltimore: Williams and Wilkins, 1988.

22 Behrman RE, Vaughan VC, Nelson WE. Infections due to the respiratory syncytial virus. In: Nelson's Textbook of pediatrics. Philadelphia: WB Saunders, 1983: 779.

23 Standing Committee of Social Welfare Administrators. 1987/8 Welstat report on adoptions (Australia). Canberra: Australian Government Printing Office, 1990.

24 Beal SM, Blundell HK. Recurrence incidence of sudden infant death syndrome. Arch Dis Child 1983; 63: 924-30.

Babson SG, Clarke NB. Relationship between infant death and maternal age. $\mathcal{F}$ Paediatr 1983; 103: 391-3.

26 Bergman AB, Weisner L. Relationship of passive cigarettesmoking to Sudden Infant Death Syndrome. Pediatrics 1976; 58: $665-8$.

27 Peterson DR. The Sudden Infant Death Syndrome: reassessment of growth retardation in relation to maternal smoking and the hypoxia hypothesis. Am $\mathcal{F}$ Epidemiol 1981; 113: 583-9.

28 Harlap S, Davies AM. Infant admissions to hospital and maternal smoking. Lancet 1974; i: 529.

29 Nicholl JP, O'Cathain A. Epidemiology of babies dying at different ages from the sudden infant death syndrome. $\mathcal{F}$ Epidemiol Community Health 1989; 43: 133-9.

30 Kraus JF. Methodologic consideration in the search for risk factors unique to sudden infant death syndrome. In: Tildon JT, Roedes LM, Steinschneider A, eds. Sudden infant deat syndrome. Baltimore: Academic Press, 1983: 43-58.

31 Goldberg J, Hornung R, Yamashita T, Wehrmacher W. Age at death and risk factors in sudden infant death syndrome. Aust Paediatr $\mathcal{F}$ 1986; 22 (suppl 1): 21-8. 